\title{
AN INTERPOLATION TECHNIQUE FOR THE METHOD OF CHARACTERISTICS IN 4-DIMENSIONS DOMAIN
}

\author{
Gamal Hafez \\ Department of General Studies, Yanbu Industrial College, \\ P.O. Box: 30436, Yanbu Al-Sinaiyah, Kingdom of Saudi Arabia. \\ E.Mail: g_hafez@hotmail.comorghafez@yic.edu.sa
}

\begin{abstract}
An interpolation procedure for unsteady inviscid flow (i.e. Euler) solvers is developed. The proposed linear interpolation is first order accurate in time $(\Delta t)$. The flow properties at each non-mesh point are interpolated in a physical manner as a summation of the values at its surrounding eight mesh points multiplied by their respective weighting coefficients. The coefficients are based on the distances apart between the interpolating non-mesh point and the eight mesh points. The major advantage in this technique is using the position vector for interpolation instead of using the three coordinates $\mathrm{x}, \mathrm{y} \& \mathrm{z}$ in succession. This means that it is a one step interpolation instead of three steps. Finally, the compatibility is achieved from using the hyper characteristic curves to locate the initial data points. The proposed technique offers an accurate, efficient and compatible interpolation valid for the method of characteristics in 4-D.
\end{abstract}

KEYWORDS: gas dynamic, method of characteristics, unsteady, 3-dimensions, interpolation.

\section{INTRODUCTION}

Careful implementation of solution methods in computational fluid dynamics has become recently more important. The simple problems have been solved while the more difficult ones have not, so far, [1]\&[2]. For the solution of Navier-Stokes equations, the method of characteristics in 4-D was applied to the hyperbolic part [3]. In this method, an interpolation technique is necessary to obtain the initial conditions and to maintain the solution stability. The objective of the present investigation was to investigate numerical interpolation procedures for unsteady inviscid flow (i.e. Euler) solvers and to develop an accurate, efficient and compatible interpolation technique valid for the method of characteristics in 4-D.

Due to its simplicity interpolating polynomials were widely used for implementation [4]\&[5]. The problems associated with polynomials in the interpolation can be summarized in two points;

1. Lack of information is occurred due to limiting the number of used mesh-points according to the number of the unknown coefficients. For example, in 3-D interpolation, out of 27-mesh-points only 11 points are enough to obtain the coefficients of a quadratic polynomial. The used 11-mesh 
points were selected according to the flow upstream direction [6].

2. Numerical instabilities are encountered due to non-physical distribution between the mesh-points.

In previous work, a weighting first-order interpolation technique was developed to deal with the characteristic surfaces of the twodimension unsteady flow [7]. Then a two-step first-order interpolation technique was used to obtain the initial data for an axisymmetric flow field [ 8]. The direct expansion of the last one for the solution of three-dimension unsteady flow field leads to a very long threestep first order interpolation technique. Therefore, an attempt to develop an interpolation technique and to avoid using polynomials for the interpolation is demonstrated in the present paper. Following this introduction, the main equations and their solution are presented. The proposed interpolation technique is then obtained.

\section{CHARACTERISTIC EQUATIONS}

The gas dynamic model in the nonconservative form can be written as follows:

$$
\begin{aligned}
& \frac{\partial \rho}{\partial t}+\frac{\partial \rho u}{\partial x}+\frac{\partial \rho v}{\partial y}+\frac{\partial \rho w}{\partial z}=0 \\
& \frac{\partial u}{\partial t}+u \frac{\partial u}{\partial x}+v \frac{\partial u}{\partial y}+w \frac{\partial u}{\partial z}+\frac{1}{\rho} \frac{\partial P}{\partial x}=0 \\
& \frac{\partial v}{\partial t}+u \frac{\partial v}{\partial x}+v \frac{\partial v}{\partial y}+w \frac{\partial v}{\partial z}+\frac{1}{\rho} \frac{\partial P}{\partial y}=0 \\
& \frac{\partial w}{\partial t}+u \frac{\partial w}{\partial x}+v \frac{\partial w}{\partial y}+w \frac{\partial w}{\partial z}+\frac{1}{\rho} \frac{\partial P}{\partial z}=0 \\
& \frac{\partial P}{\partial t}+u \frac{\partial P}{\partial x}+v \frac{\partial P}{\partial y}+w \frac{\partial P}{\partial z}+\rho a^{2}\left[\frac{\partial u}{\partial x}+\frac{\partial v}{\partial y}+\frac{\partial w}{\partial z}\right]=0
\end{aligned}
$$

The solution of the above hyperbolic partial differential system of equations (1), (2) \& (5) may obtained in the following form[3].

$$
\begin{gathered}
d P+\rho a[\cos \alpha d u+\cos \beta d v+\cos \gamma d w] \\
=\rho a^{2} S d t
\end{gathered}
$$

Provided that

$\frac{d x}{d t}=u+a \cos \alpha, \quad \frac{d y}{d t}=v+a \cos \beta$,

and $\frac{d z}{d t}=w+a \cos \gamma$

The energy Eq. (5) can be also transformed to the following form;

$d P=-\rho a^{2}\left[\frac{\partial u}{\partial x}+\frac{\partial v}{\partial y}+\frac{\partial w}{\partial z}\right] d t$

Provided that

$\frac{d x}{d t}=u, \quad \frac{d y}{d t}=v, \quad$ and $\quad \frac{d z}{d t}=w$

The compatibility equations (6)\&(8) were numerically integrated along the characteristic conditions (7) \&(9) respectively. The discretization of the domain of solution for any interior point is shown in Fig. 1. In this Fig., an incomplete rectangular prism of an interior point is shown by only omitting four points from the twenty six points surrounding the interior point in order to clearly represent the initial domain of solution. The spherical domain of dependency represents all points that are communicating with the interior point of solution over $\Delta \mathrm{t}$ time increment. On the other hand, the outside points to the spherical domain of dependency are not affecting, by any way, the interior point of solution. Therefore, the use of information from outside the spherical domain of dependency leads to instability problems. Accordingly, any point on the surface of the spherical domain of dependency can be used as initial values for the numerical integration of the compatibility relations. This offers infinite number of points and hence infinite number of compatibility relations. A finite number of points is required in order to simulate all transported information across the time interval $\Delta \mathrm{t}$. The number of points 
was controlled by choosing the proper number of hyper-characteristic curves.

Six different directions were chosen to construct the wave hyper-curves Eq.(7) [3]. The six hyper-curves projected rearward from the new point to the earlier time domain. They intersect with the earlier time domain in six non-mesh points. One more non-mesh point was obtained by using the stream hypercurve Eq.(9). A graphical representation to visualize the hyper-characteristic net in 4-D domain is shown in Fig. 2. In this Fig., the domain of solution, the rectangular prism in Fig. 1, was represented as a hexagon in which the spherical domain of dependency was transformed to an ellipse.

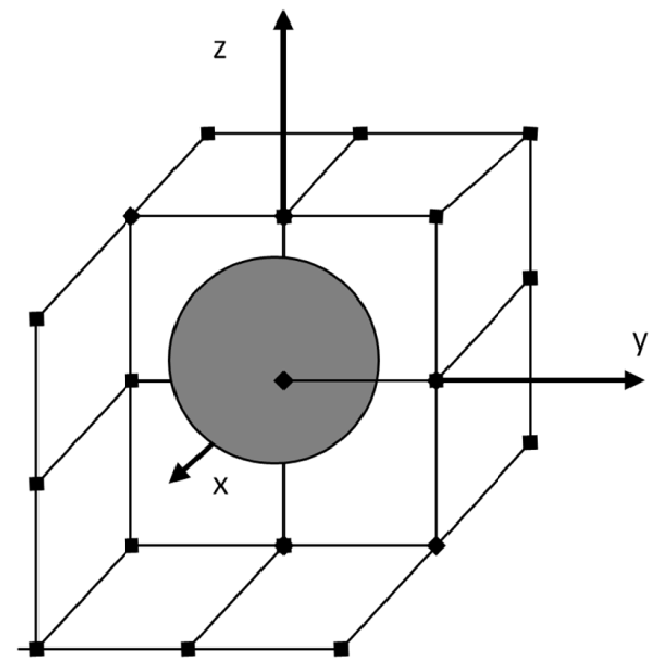

Fig. 1. The initial domain of dependency.

The point $\mathrm{P}$ is the interior point of solution after $\Delta \mathrm{t}$ time increment that was impossible to be shown in Fig. 1. The six hypercharacteristic curves drawn in dashed lines from point $P$ to points 1-6 on the surface of the spherical domain of dependency. The stream hyper-curve drawn in center line form from point $\mathrm{P}$ to point 7 in the center of the spherical domain of dependency.

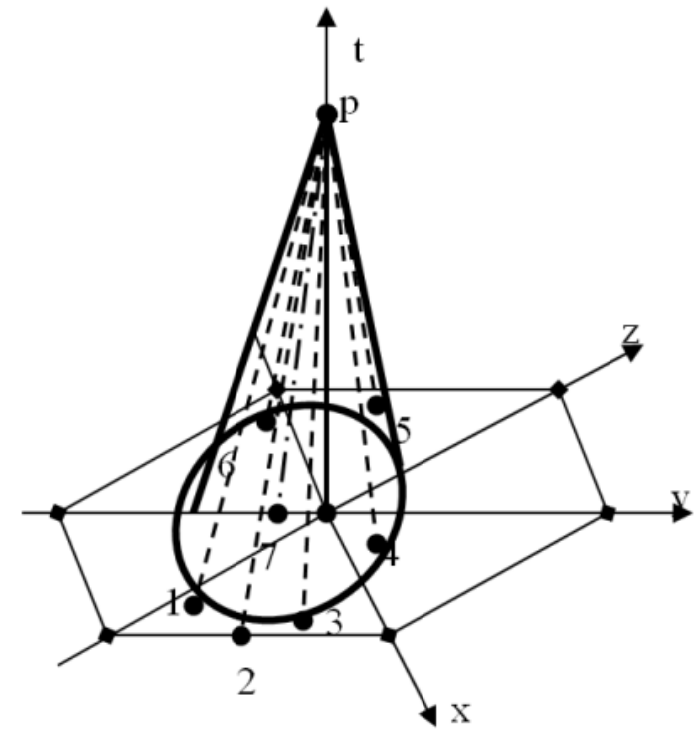

Fig. 2. The hyper-characteristic net.

Regarding these non-mesh points, some interpolation procedure is required to obtain their values.

\section{PROPOSED INTERPOLATION TECHNIQUE}

The interpolation is required for stability needs to determine the flow parameters at the non-mesh points of the initial domain of solution. There exist 27 -mesh points that can be used to interpolate the 7-non-mesh points. For each non-mesh point there exist only 8mesh points which can be used for the interpolation of that point. In order to proceed in the interpolation technique, the location of the non-mesh points must be determined and then the corresponding 8mesh points can be specified. Equations.(7) \&(9) are used to determine the components of the position vector of each non-mesh point as follows:

$\underline{r}_{i}=\left(\Delta x_{i}, \Delta y_{i}, \Delta z_{i}\right) \quad, i=1,2, . ., 7$

where

$$
\begin{array}{ll}
\Delta x_{i}=(u+a \operatorname{Cos} \alpha)_{i} \Delta t, & \Delta x_{7}=u_{7} \Delta t \\
\Delta y_{i}=(v+a \operatorname{Cos} \beta)_{i} \Delta t, & \Delta y_{7}=v_{7} \Delta t
\end{array}
$$


$\Delta z_{i}=(w+a \operatorname{Cos} \gamma)_{i} \Delta t, \quad \Delta z_{7}=w_{7} \Delta t$

There exist eight possible locations for the seven non-mesh points according to the sign of the components $\Delta \mathrm{x}_{\mathrm{i}}, \Delta \mathrm{y}_{\mathrm{i}}$ and $\Delta \mathrm{z}_{\mathrm{i}}$. These eight rectangular prisms are shown in Fig. 3.

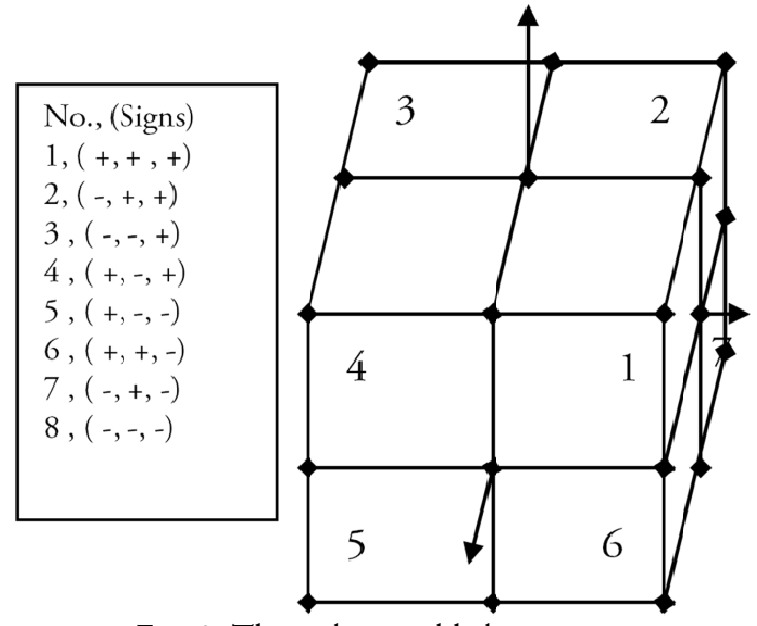

Fig. 3. The eight possible locations.

Consider a non-mesh point located in the rectangular prism No. 1, Fig. 4. In this Fig., the eight distances between the non-mesh point and the eight mesh points are drawn in dashed lines and then calculated as follows:

$l_{k}=\sqrt{\left(\Delta_{1}^{2}+\Delta_{2}{ }^{2}+\Delta_{3}{ }^{2}\right)_{k}}, \quad k=1,2, \ldots, 8$

where $\Delta_{1}, \Delta_{2}$ and $\Delta_{3}$ are the Cartesian components of $l_{\mathrm{k}}$.

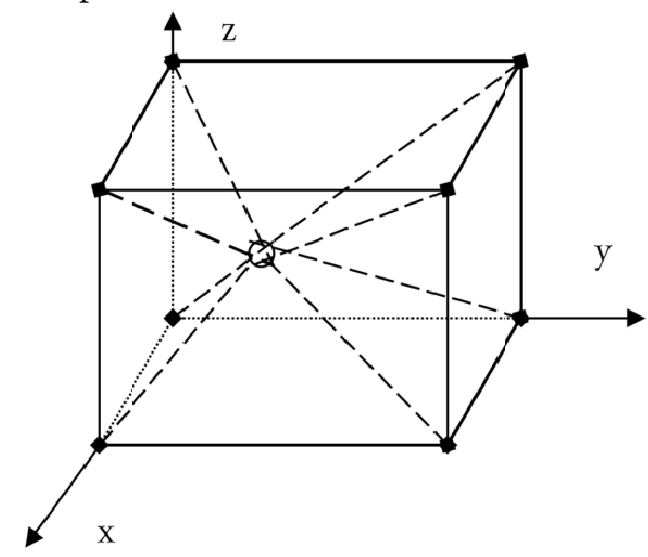

Fig. 4. The eight distances between the non-mesh point and the eight mesh points.

The flow properties at each non-mesh point interpolated in a physical manner as a summation of the values at its surrounding eight mesh points multiplied by their respective weighting coefficients.

$\varphi_{j}=\sum_{k=1}^{8} L_{k} \varphi_{k}^{p}, \quad j=1,2, \ldots, 7$

The coefficients are based on the distances between the interpolating point and the eight mesh points.

$$
L_{k}=\frac{\frac{1}{l_{k}}}{\sum_{j=1}^{8} \frac{1}{l_{j}}}
$$

\section{TEST MODEL}

The proposed interpolation technique is tested against the following distribution: $\varphi=e^{x^{n}+y^{n}}$

where $\mathrm{n}$ is any real number. $\mathrm{n}$ is added to control the variation along with the distribution where the interpolation accuracy is dependent to the maximum variation (MV).through a distribution.

$$
\begin{aligned}
& M V=\frac{\varphi_{\max }}{\varphi_{\min }} \\
& \text { Accuracy }=\min \left(\frac{\varphi_{\text {exact }}-\left|\varphi_{\text {int erpolated }}-\varphi_{\text {exact }}\right|}{\varphi_{\text {exact }}}\right)
\end{aligned}
$$

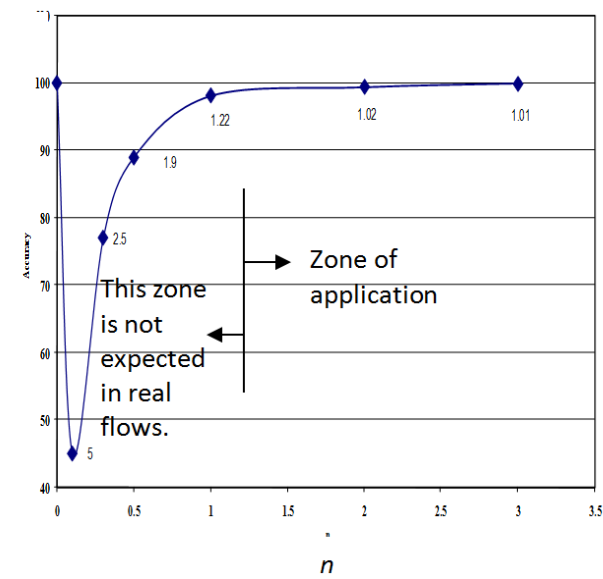

Fig. 5. The interpolation accuracy for different distributions 
Fig. 5 shows the interpolation minimum accuracy of different distributions (n) where the corresponding $\mathrm{MV}$ is written beside the labels at each point. The figure shows that the interpolation can fit a wide range of distributions under a reasonable high MV in contrast with real flows. It is also concluded from the results that sufficient accuracy can be obtained provided that MV is minimized.

\section{CONCLUSIONS}

The proposed linear interpolation is first order accurate in time $(\Delta \mathrm{t})$. The major advantage in this technique is using the position vector for interpolation instead of using the three coordinates $\mathrm{x}, \mathrm{y} \& \mathrm{z}$ in succession. This means it is a one step interpolation instead of three steps. The interpolation of the seven non-mesh points requires the whole 27 -mesh points to be used. The present interpolation technique successfully avoids the use of polynomials, which govern the distribution between the mesh points in non-physical manner. The proposed technique uses the minimum MV because it interpolates over only one cell instead of using eight cells in case of polynomials. Finally, the compatibility is achieved from using the hyper characteristic curves to locate the initial data points. Providing all the values at the interpolating points, the numerical integration of the compatibility relations along the characteristic hyper-curves can be implemented. Therefore the proposed technique provides a simple interpolation method and can be considered as compatible, efficient and accurate enough to be used for the numerical simulations of real fluid flow problems.

\section{NOMENCLATURE}

$\alpha \quad$ Characteristic angle with $\mathrm{x}$-axis.

$\beta \quad$ Characteristic angle with $y$-axis.

$\gamma \quad$ Characteristic angle with z-axis.

P Local pressure.

$\rho \quad$ Local density.

S Source term.

$\mathrm{u} \quad$ Velocity component in $\mathrm{x}$-direction.

$\mathrm{v} \quad$ Velocity component in y-direction.

$\varphi \quad$ Any transportable property at a nonmesh point.

$\varphi^{\mathrm{p}} \quad$ Any transportable property at a mesh point.

w Velocity component in z-direction.

\section{REFERENCES}

[1] Arthur M. T.: Unsteady, three-dimensional flows and the need for new developments in CFD, third Asian CFD Conf., Bongalore, India, Dec. 7-11, 1998.

[2] Chalot F., Dinh Q. V., Mallet M., Marquez B., Ravachol M., Roge G. and Stoufflet B.: Present capabilities and future trends for CFD in aeronautics, third Asian CFD Conf., Bongalore, India, Dec. 7-11, 1998.

[3] Hafez G. H. M.: Numerical solution of NavierStokes equations in four independent variables, Al-Azhar Eng. Sixth Int. Conf., Egypt, Sep. 1-4, 2000.

[4] Marcum D. L. and Hoffman J. D.: Calculation of unsteady three-dimensional subsonic/transonic flow-fields by the method of characteristics, AIAA $22^{\text {nd }}$ aerospace sciences meeting, Jan. 9-12, 1984.

[5] Marcum D. L. and Hoffman J. D.: Calculation of three-dimensional flow-fields by the unsteady method of characteristics, AIAA journal, Vol. 23, No. 10, Oct. 1985.

[6] Dai W. and Chen C. J.: Explicit finite analytic method for unsteady three-dimensional NavierStokes equations, Num. Heat Transfer, Part B, 33: 339-353, 1998. 
[7] Hafez G. \& Morgan.A.: Numerical Solution of Inviscid Two-Dimensional Unsteady flow by the Method of Characteristics, $4^{\text {th }}$ International Conference of Fluid Mechanics, Alexanderia, Egypt, 1992.

[8] Hafez G., Morgan A. \& Massoud S.: The Solution of Unsteady Turbulent Flows by Using the Splitting Technique and the method of characteristics, Int. Cong. on Fluid Dynamics \& Propulsion (ASME Int.), Egypt, 1996. 


\section{أسلوب إستيفاء لطريقة الخصائص في مجال رباعي الأبعاد \\ جمال حافظ \\ قسم العلوم الأساسية - كلية ينبع الصناعية، المعلكة العربية السعودية}

الملخص:

تم استحداث اسلوب إستيفاء للسريان المتغير ذو دقة من الدرجة الاولى في الزمن. تم حساب الخواص عند أي نقطة بينية كمجوع لقيم الخاصية عند الثمان نقط المحيطة بعد ضرب كل قيمة بمعامل التأثير الخاص بها. تم حساب معامل التأثير لنقطة ما من الثمان نقط على أساس مقلوب المسافة بين النقطة نفسها والنقطة البينية . ويتميز الاسلوب المقترح باستخدام متجه الموضع لإستيفاء القيم بدلا من استخدام الثلاث محاور x, y \& z التو الي. ويعني هذا ان الطريقة المقترحة تحتاج خطوة واحدة للإستيفاء بدلا من ثلاث خطو ات. ويتم التو افق في الاسلوب المقتر ح مع الحل العام لمعادلات السريان بواسطة استخدام منحنيات الخصائص الز ائدية لتحديد أماكن النقط البينية وهي النقط الابتدائية للحل. ومن ثم يعد الاسلوب المقترح متوافق مع الحل العام لمعادلات السريان وبدقة كافية للنطبيق في طريقة الخصائص خاصة وللسريان الحقيقي عامة. 